\title{
Epistaxis-Incidence, Etiology, and Management: A Hospital-based Study
}

\author{
${ }^{1}$ Niru Moran, ${ }^{2}$ Debajit Das
}

\begin{abstract}
Epistaxis is defined as bleeding from the nose. Though it is not serious, it causes anxiety both to the sufferer and to the attending physician. The objective of this study was to review the incidence, common etiological factors, and management modalities of epistaxis. It is a prospective study of 288 patients seen with epistaxis over 1.5 years at Assam Medical College and Hospital from January 2014 to July 2015. The age of patients ranged between 4 and 80 years. An incidence of $7.5 \%$ $(38,400)$ was recorded and slight male preponderance with a male:female ratio of 25:9. Trauma and local nasal factor were the main etiological factors identified, but over $5.90 \%$ had no discernable cause. About $65 \%$ presented with active bleeding and $50 \%$ required admission. Patients were managed according to their cause. About $10.41 \%$ required blood transfusion. Epistaxis is a common rhinological emergency that requires prompt intervention to reduce morbidity and prevent mortality.
\end{abstract}

Keywords: Blood transfusion, Epistaxis, Rhinological.

How to cite this article: Moran N, Das D. EpistaxisIncidence, Etiology, and Management: A Hospital-based Study. Clin Rhinol An Int J 2016;9(1):18-20.

\section{Source of support: Nil}

Conflict of interest: None

\section{INTRODUCTION}

Bleeding from the nose and nasopharynx is a common symptom of diverse conditions, which may present as mild recurrent bleeds or severe life-threatening rhinological emergency and may pose a challenge to even a skilled otolaryngologist. ${ }^{1}$ Globally, the true incidence remained unknown, but it is estimated that $60 \%$ of the population will have at least an episode of epistaxis in their lifetime and $6 \%$ of them will seek medical attention. ${ }^{2}$

Epistaxis can be anterior or posterior. According to Pearson, ${ }^{3}$ the term posterior epistaxis as a bleeding point could not be located despite examination with a headlight, vasoconstrictors, and suction. Anterior epistaxis is bleeding from a source anterior to the plane

\footnotetext{
${ }^{1}$ Postgraduate Student, ${ }^{2}$ Professor

1,2Department of ENT, Assam Medical College, Dibrugarh Assam, India

Corresponding Author: Niru Moran, Postgraduate Student Department of ENT, Assam Medical College, Dibrugarh, Assam India, Phone: +919706449377, e-mail: kaminimoran3@gmail. com
}

of the pyriform aperture. This includes bleeding from the anterior septum and rare bleeds from the vestibular skin and mucocutaneous junction. Posterior epistaxis is bleeding from a vessel situated posterior to the pyriform aperture.

\section{Structured Clinical Classification ${ }^{4}$}

Primary No proven factors

Secondary Proven causal factor

Childhood $<16$ years

Adult $>16$ years

Anterior Bleeding point anterior to pyriform aperture

Posterior Bleeding point posterior to pyriform aperture

The nose is supplied by external and internal carotid artery via branches that anastomose extensively within the lateral wall, septum, and across the midline. James Little (1879) described an arterial plexus, which is situated on the anterior septum as a frequent site of bleeding, and the same plexus was described 1 year later by Kiesselbach. ${ }^{5}$ The external carotid artery supplies the nasal cavity via facial and maxillary branches. The sphenopalatine artery is the most important supply to the nasal cavity.

\section{External Carotid Artery ${ }^{4}$}

Facial artery - Superior labial artery, lateral nasal artery, ascending palatine artery.

Maxillary artery - Greater palatine artery and sphenopalatine artery - Lateral nasal branch and posterior septal branch.

Internal carotid artery - Anterior ethmoidal artery and posterior ethmoidal artery.

The peak incidence of adult primary epistaxis is in the 6th decade having slightly male predominance. The most common site of posterior epistaxis in adults is inferior to the posterior end of the inferior turbinate, also known as Woodruff's plexus.

The adult primary epistaxis is greatest in the autumn and winter months. ${ }^{6}$ The seasonal variation correlates with fluctuations in environmental temperature and humidity.

Recurrent bleeding commonly occurred in children, when recurrent bleeds occur in adults, common cause will be secondary. 
Our aim of this study was to analyze the incidence, etiology, and management of epistaxis.

\section{MATERIALS AND METHODS}

The study was conducted in the Department of Otorhinolaryngology and Head Neck Surgery and Emergency department of Assam Medical College and Hospital, Dibrugarh, Assam, India, between January 2014 and July 2015. A total of 288 cases were included in this study. A total of 38,400 patients attended in a outpatient department Otorhinolaryngology and referred patient from other department of Assam Medical College. Parameters included demographics, concomitant medical conditions, drug history, month of presentation, trigger of bleeding, examination findings, treatment modality, and complications. The data were analyzed using standard statistical methods.

\section{RESULTS AND OBSERVATIONS}

A total of 38,400 patients were seen at the institute during the period. Of these, 288 patients had epistaxis as a presenting complaint.

Incidence rate was $7.5 \%$. A total of 212 patients were male and 76 patients were female (Graph 1). Males predominated with a male:female ratio of 25:9. Out of the 288 patients, 167 (57.97) cases were due to trauma, deviated nasal septum (DNS) and spur 31 (10.76), hypertension $21(7.29 \%)$, idiopathic 17 (5.90\%), chronic liver disease 17 (5.90\%), juvenile angiofibroma (JNA) $15(5.20 \%)$, foreign body (FB) 13 (4.51\%) leukemia 4 (1.38\%), and blood dyscrasia 3 (1.04\%) (Table 1).

Age range was from 4 to 80 years. Peak presentation in the 21 to 30 years age group was $78(27.08 \%), 31$ to 40 years $118(40.97 \%), 1$ to 10 years $21(7.29 \%), 11$ to 20 years 25 $(8.68 \%), 41$ to 50 years $17(5.90 \%), 51$ to 60 years $13(4.51 \%), 61$ to 70 years $10(3.47 \%)$, and 71 to 80 years $6(2.08 \%)$ (Graph 2).

Patients presented with mild-to-severe epistaxis. Those who were bleeding slightly did not require admission. Out of 288 patients, 187 (64.93\%) needed

Table 1: Etiological factors

\begin{tabular}{ll}
\hline Etiological factor & $\begin{array}{l}\text { No. and Percentage } \\
n=288\end{array}$ \\
\hline 1. Trauma & $167(57.97)$ \\
2. Deviated nasal septum and spur & $31(10.76)$ \\
3. Hypertension & $21(7.29)$ \\
4. Idiopathic & $17(5.90)$ \\
5. Chronic liver disease & $12(4.16)$ \\
6. Juvenile angiofibroma & $15(5.20)$ \\
7. Foreign body & $13(4.51)$ \\
8. Blood dyscrasia & $8(2.77)$ \\
9. Leukemia & $4(1.38)$ \\
\hline & Total $=288(100)$ \\
\hline
\end{tabular}

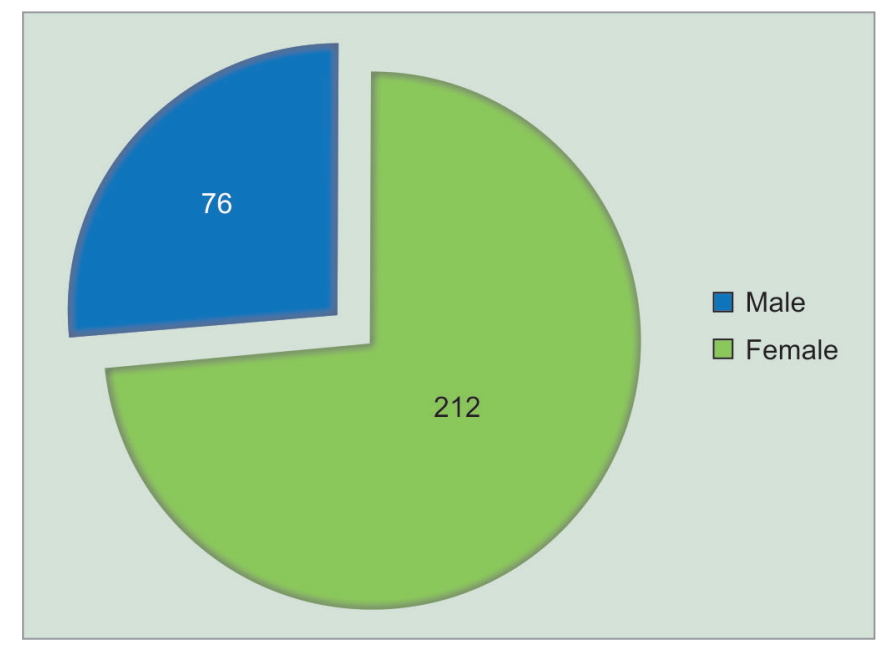

Graph 1: Male to female ratio

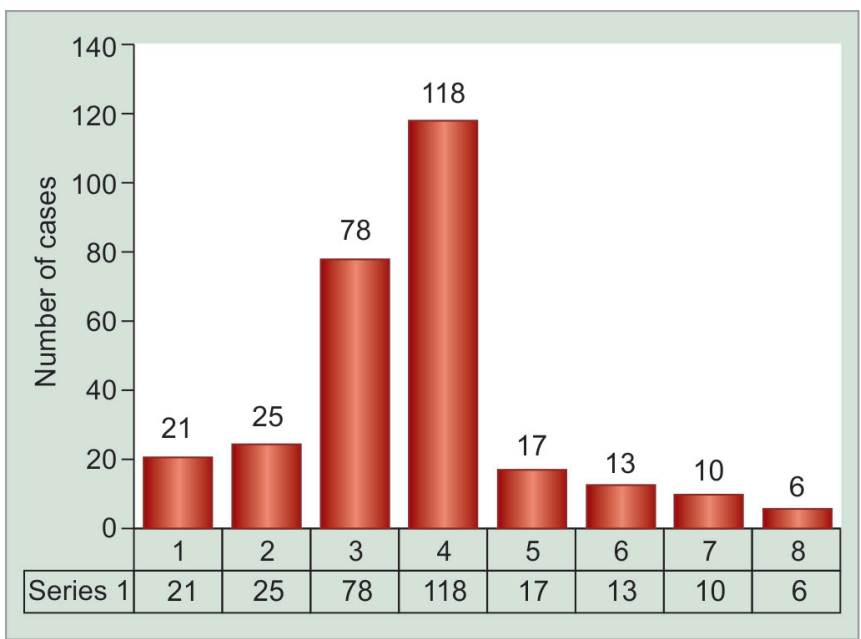

Graph 2: Age distribution

anterior nasal packing (ANP), 20 (6.94\%) underwent septoplasty, 15 (5.21\%) were administered transpalatine approach for removal of JNA, 8 required cautery $(2.77 \%)$, and $6(2.08 \%)$ needed anterior and posterior nasal packing (Table 2).

In most of the cases of children, epistaxis was due to FB and habit of nose pricking and in the elderly age group mainly due to uncontrolled hypertension. Thirty patients required blood transfusion.

All routine investigations were sent along bleeding profile. Some special investigations were for trauma

Table 2: Treatment

\begin{tabular}{ll}
\hline Treatment & $\begin{array}{l}\text { No. of patients and \% } \\
n=288\end{array}$ \\
\hline $\begin{array}{l}\text { Anterior nasal packing (ANP) } \\
\text { Septoplasty }\end{array}$ & $187(64.93)$ \\
$\begin{array}{l}\text { Transpalatine approach for juvenile } \\
\text { angiofibroma }\end{array}$ & $15(6.94)$ \\
Cautery & \\
ANP and posterior nasal packing & $8(2.77)$ \\
\hline
\end{tabular}


from road traffic accident: Computed tomography scan, faciomaxillary region, $\mathrm{X}$-ray nose and paranasal sinus for DNS, electrocardiogram to look for any cardiac pathology.

\section{DISCUSSION}

In spite of the anxiety generated by nose bleeding, it can be cured by the first attending physician if prompt and appropriate intervention is made. ${ }^{8}$ Epistaxis may manifest as a severe picture that requires hospital admission; it affects all age ranges and occurs with a higher frequency in elderly and male patients. ${ }^{9,10}$

In children, it generally comes from the anterior region of the nasal cavity and is caused by local alterations; in most adults, it is associated with systemic alterations and comes from the posterior part of the nasal cavity. ${ }^{9}$

In this study, its incidence was $7.5 \%$. The age ranged from 4 to 80 years and the male to female ratio is $25: 9$. The treatment may be by anterior nasal pack, anteroposterior nasal pack, electrocauterization, chemical cauterization, endoscopic arterial ligation (with clip or cauterization), embolization, and other surgical management. The bleeding point, if found, is cauterized either with silver nitrate or with electrocautery. Failure to find the bleeding point leads to anterior nasal pack with antibiotic coverage, merocele, when available.

Our study carried out ANP in 187 patients (64.93\%), anteroposterior splint in $6(2.08 \%)$, bleeding point cauterization (chemical and electro) in 8 patients $(2.77 \%)$, septoplasty in $20(6.94 \%)$, and transpalatine approach for JNA removal in 15 (5.21\%); no patient was submitted to embolization and endoscopic ligation of arteries.

Venosa et $\mathrm{al}^{11}$ said that the patients are submitted to conservative methods of treatment before the performance of endoscopic arterial ligation.

The epistaxis for external trauma was seen in 167 $(57.9 \%)$, no prevailing factor was identified as a cause of bleeding in 17 (5.90\%).

Increased incidence was seen in winter months and dry/hot months in most of the cases of idiopathic epistaxis in our studies.

Similar studies were seen in McGarry, ${ }^{4}$ Bhatia and Varughese ${ }^{12}$ with increased incidence due to high wind velocity and dryness, which favor crust formation in the nasal cavity.

\section{CONCLUSION}

The management of epistaxis is a wide range of strategies and treatment options. It is important to appreciate when to correctly employ the different individual interventions. Nasal saline spray can help prevent nosebleeds, especially during the winter months. Epistaxis is a common rhinological emergency that requires prompt intervention to reduce morbidity and prevent mortality.

\section{REFERENCES}

1. Nnnennia CM. Epistaxis in Enugu: a 9 years review. Nigerian J Otorhinolaryngol 2004;1(1):11-14.

2. Varshney S, Saxena RK. Epistaxis: a retrospective clinical study. Indian J Otolaryngol Head Neck Surg 2005 Apr;57(2): 125-129.

3. Pearson BW. Epistaxis: some observations on conservative management. J Laryngol Otol 1983 Jan;(Suppl 8):115-119.

4. McGarry, GW. Epistaxis, Scott-Brown's otorhinolaryngology, head and neck surgery.7th ed. Vol. 2. In:Gleeson M.;Clarke, RC., editors London: Hodder Arnold, 2008. p. 1596-1606.

5. Mackenzie D. Little's area or the locus Kiesselbachii. J Laryngol 1914;1:21-22.

6. Nunez DA, McClymont LG, Evans RA. Epistaxis: a study of the relationship with weather. Clin Otolaryngol 1990 Feb;15(1): 49-51.

7. Danielides V, Kontogiannis N, Bartzokas A, Lolis CJ, Skevas A. The influence of meteorological factors on the frequency of epistaxis. Clin Otolaryngol Allied Sci 2002 Apr;27(2):84-88.

8. Kodiya AM,Labaran AS, Musa E, Mohammed GM,Ahmad BM. Epistaxis in Kaduna, Nigeria: a review of 101 cases in a resource constrained setting. J Clin Med Res 2014 Jan;6(1):1-4.

9. IkinoCMY,D'Antôn WE,MurakamiMS, Miziara ID, ButuganO. Epistaxes recorrentes: Estudo dos fatores clínicos elaboratoriais associados. Rev Bras Otorrinolaringol 1999 Mar-Apr;65(2 Pt 1): 149-153.

10. Lubianca Neto JF, Fuchs FD, Facco SR, Gus M, Fasolo L, Mafessoni R, Gleissner AL. Is epistaxis evidence of end-organ damage in patients with hypertension? Laryngoscope 1999 Jul;109(7 Pt 1):1111-1115.

11. Venosa A, Butugan O, Voegels RL, et al. Epistaxe Severa: Estudo Retrospectivo. Rev Bras Otorrinolaringol 1998 JanFeb;64(1):57-60.

12. Bhatia PL, Varughese R. Pattern of otolaryngological diseases in Jos community. Nigeria Med J 1987;17:67-73. 